\title{
Effect of hepatitis C antiviral therapy on oral lichen planus and hyposalivation in inmates
}

\author{
Giuseppe Scelzaa , Alessandra Amato ${ }^{a}$ Antonio Maria Paganob, Giuseppe De Matteis ${ }^{b}$, Rosa Carusob, \\ Antonio Scelza ${ }^{b}$, Laura Sisallia, Sebastiana De Biasi' ${ }^{b}$ Francesca Mariglianob, Mario Gagliardic, \\ Stefano Martina ${ }^{a}$, Alfredo landolo ${ }^{a}$
}

University of Salerno; Penitentiary Institute, Salerno, Italy

\section{Abstract}

\begin{abstract}
Background Oral lichen planus (OLP) and hyposalivation have been reported as extrahepatic manifestations of hepatitis $\mathrm{C}$ virus (HCV) infection. Our study evaluated the effect of direct antiviral agents (DAAs) on OLP and hyposalivation in convicts with chronic hepatitis $\mathrm{C}$, examining patients before, during and after the antiviral treatment period with direct acting antiviral agents (DAAs).

Methods We screened 198 inmates for the presence of the HCV antibody. Patients found to be positive underwent a quantitative HCV-RNA test and HCV genotype typing, as well as an oral cavity examination using a scoring system for OLP (REU score) and the clinical oral dryness score (CODS). Subsequently, all patients underwent DAA therapy and a systematic physical examination of the oral cavity at 1,3 and 6 months from the beginning of treatment.
\end{abstract}

Results Fifty patients (25.25\%) had a positive HCV-RNA test. At baseline, OLP was detected in 4 patients (8\%), with a mean REU score of $10.13 \pm 4$, and different degrees of hyposalivation were seen in 17 patients (34\%), with a mean CODS score of $4.71 \pm 1.72$. Six months after the start of DAA therapy, we observed resolution of OLP in 3 patients (75\%) and improvement in the remaining subject with a significantly lower mean REU score $(2 \pm 4)$. Hyposalivation disappeared in 5 patients, improved in 10 , and remained unchanged in 2 patients with a significantly lower mean CODS score $(0.06 \pm 0.24)$.

Conclusion This study demonstrated the effectiveness of DAAs in the treatment of OLP and hyposalivation.

Keywords Direct antiviral agents, hepatitis C virus, oral lichen planus, hyposalivation, prison

Ann Gastroenterol 2021; 34 (1): 1-6

\section{Introduction}

Hepatitis $\mathrm{C}$ virus (HCV) infection is a widespread disease with a global estimate of 71 million individuals chronically

${ }^{a}$ Department of Medicine and Surgery, University of Salerno (Giuseppe Scelza, Alessandra Amato, Laura Sisalli, Stefano Martina, Alfredo Iandolo);

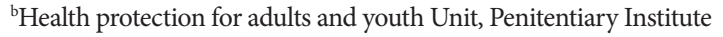
(Antonio Maria Pagano, Giuseppe De Matteis, Rosa Caruso, Antonio

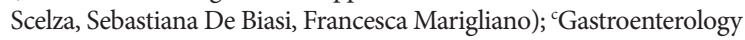
Unit, Department of Medicine, Surgery and Dentistry "Scuola Medica Salernitana”, University of Salerno (Mario Gagliardi), Salerno, Italy

Conflict of Interest: None

Correspondence to: Mario Gagliardi, MD, Digestive Endoscopy Unit, University Hospital “San Giovanni di Dio e Ruggi d'Aragona”, Salerno, Italy, e-mail: mariogagliardi@outlook.com

Received 11 June 2021; accepted 8 August 2021 published online 10 November 2021

DOI: https://doi.org/10.20524/aog.2021.0672 infected [1]. Chronic hepatitis has a progressive evolution and can lead to cirrhosis in $20-30 \%$ of infected patients over 20-30 years. Each year, 1-5\% of patients with cirrhosis develop hepatocellular carcinoma [2]. Prison represents a confined environment characterized by great exposure and risk of infection [3]. In fact, in prison there are various risk categories, such as patients who inject drugs intravenously (PWID), people living with human immunodeficiency virus (HIV), and men who have sex with men, that increase the risk of HCV infection [4]. The worldwide prevalence of $\mathrm{HCV}$ infection recorded within prison is $26 \%$ [5]. Within Italian prisons, the prevalence of HCV infection varies from $22-38 \%$ [6].

Approximately $74 \%$ of individuals with $\mathrm{HCV}$ infection develop extrahepatic manifestations, many of which affect the oral cavity [7]. The reported oral lesions are xerostomia, Sjögren's syndrome, sialadenitis, oral lichen planus, bleeding disorders, gingivitis, cheilitis, smooth and atrophic tongue [8].

Oral lichen planus (OLP) is a chronic cell-mediated inflammatory disease of the oral mucosa that typically affects buccal mucosa, tongue and gingiva with bilateral and symmetric 
lesions. There are 6 different forms of lichen: reticular, papular, plaque-like, atrophic/erosive, ulcerative and bullous [9]. The prevalence of OLP ranges from $0.5-2.2 \%$ in the general population and develops more frequently between the third and sixth decade of age [10]. The prevalence of OLP in patients with HCV varies from 1.5\% in North America and Northern Europe to 1.5-3.5\% in Western and Eastern Europe and up to 35\% in Egypt, Japan and Southern Europe [11]. Nevertheless, the pathogenic link between HCV and OLP is still not completely understood $[12,13]$.

Xerostomia, or hyposalivation, is the reduction of salivary flow due to alteration of the function of the salivary glands [14]. The prevalence of xerostomia ranges from 12-30\%, affecting women more than men [15]. Systemic diseases and local conditions can be the cause of xerostomia [16]. The signs of hyposalivation that can be detected are alterations in ingestion, alterations in taste (dysgeusia), atrophic mucous membranes, halitosis, cervical caries, cheilitis and candidiasis [15,17].

Patients with chronic HCV infection have a prevalence of hyposalivation between $13 \%$ and $33 \%$. Early studies by Haddad et al have shown the existence of an association between HCV and salivary gland disorders, although this association is still a matter of debate [18-20].

The goal of HCV antiviral therapy is the sustained virological response (SVR), defined as a negative HCV-RNA test 12 weeks after the end of the treatment. The introduction of new direct acting antiviral agents (DAAs), without interferon, allow a high SVR to be achieved with fewer and milder side effects compared to previous therapeutic protocols [21-24].

The aim of our study was to evaluate oral manifestations in patients held in prison, particularly in patients with chronic $\mathrm{HCV}$ liver disease, focusing on the evolution of OLP and hyposalivation by examining patients before, during and after the antiviral treatment period with DAAs. There are only a few case reports analyzing the effect of HCV therapy on OLP $[25,26]$, while there is a lack of studies regarding the effect of HCV therapy on hyposalivation.

\section{Patients and methods}

We investigated the prevalence of oral lesions in HCV inmates seen at the Health Department of Salerno (C.C. of Fuorni and ICATT of Eboli) from January to August 2019. We screened all 198 inmates for the presence of HCV antibodies (anti-HCV test), of whom 50 (25.25\%) tested positive. All subsequently underwent a quantitative HCV-RNA test and HCV genotyping.

HCV-RNA positive patients were selected to begin therapy with DAAs for HCV infection. Therapy consisted of glecaprevir/ pibrentasvir (Maviret) and lasted 16 weeks for 2 patients and 8 weeks for the remaining patients. None of them stopped treatment and none ever underwent interferon therapy. Each patient with HCV infection was monitored (HCV-RNA quantitative testing) before the initiation of therapy (baseline), and then 1,2, 5 or 7 months after starting therapy. At 5 months we evaluated the SVR12 in the patients who underwent the 8 -week therapy, while at 7 months we measured the SVR12 in the patients who underwent the 16-week therapy.

\section{Assessment of HCV infection and liver disease}

The anti-HCV test was the serum ELISA test (enzymelinked immunosorbent assay), while the HCV-RNA test used real-time polymerase chain reaction (real-time PCR). The HCV genotype was recorded by PCR. Transient elastography (Fibroscan) was performed in all patients to assess liver fibrosis. In addition, transaminases, platelets, Child-Pugh score, and HIV status were evaluated.

\section{Oral manifestation}

In the second phase of the study, all HCV-RNA positive convicts underwent a systematic examination of the oral cavity and perioral soft tissues to identify and record their oral status. The clinic examination was performed before the start of DAA therapy and 1, 2, 3 and 6 months after the start of treatment to monitor the evolution of OLP lesions and hyposalivation. Protocols were observed to reduce the infectious risk linked to the distance of less than one meter between the doctor and the patient. This reduced distance makes the healthcare professional more vulnerable to contact with saliva, blood and other body fluids [27].

\section{OLP}

OLP lesions were identified and diagnosed through clinical signs. The severity of OLP lesions was evaluated and monitored based on a semiquantitative scoring system (REU: reticular/ hyperkeratotic, erosive/erythematous, ulcerative) developed by Siribang-on Piboonniyom et al [28]. The scoring system divides the oral cavity into 10 sites and evaluates the severity of the OLP in relation to the type of lesion in each of the 10 areas. For reticular/hyperkeratotic lesions the score ranges from $0-1(0=$ no white striations, $1=$ presence of white striations or keratotic papules); erosive/erythematous areas were scored from $0-3$ by area of involvement $(0=$ no lesion, $1=$ lesions less than $1 \mathrm{~cm}^{2}, 2=$ lesions from $1-3 \mathrm{~cm}^{2}, 3=$ lesions greater than $3 \mathrm{~cm}^{2}$ ); ulcerative lesions were scored from $0-3$ by area of involvement $\left(0=\right.$ no lesion, $1=$ lesions less than $1 \mathrm{~cm}^{2}, 2=$ lesions from $1-3 \mathrm{~cm}^{2}, 3=$ lesions greater than $\left.3 \mathrm{~cm}^{2}\right)$. For each of the 3 types of lesions, a score was derived by summing the scores of all 10 areas: reticular score $=\Sigma \mathrm{R}$, erythema score $=$ $\Sigma \mathrm{E}$, and ulcerative score $=\Sigma \mathrm{U}$ (REU score) with a total score of $\Sigma \mathrm{R}+\Sigma(\mathrm{E} \times 1.5)+\Sigma(\mathrm{U} \times 2.0)$.

\section{Hyposalivation}

The evaluation of oral dryness and hyposalivation in patients with HCV infection was based on the clinical oral dryness score (CODS) [17]. The CODS is a 10-point score in which each point is associated with a characteristic sign of oral dryness: 1) mirror sticks to the buccal mucosa; 2) mirror sticks to the tongue; 3 ) tongue lobulated/fissured; 4) tongue shows loss of papillae; 5) frothy saliva; 6) no saliva pooling on the floor of the mouth; 7) glassy 
appearance of other oral mucosa, especially palate; 8) debris on the palate (excluding debris under dentures); 9) altered/smooth gingival architecture; and 10) active or recently restored (last 6 months) cervical caries ( $>2$ teeth). Each sign found has a value of 1 point and the total score corresponds to their sum. The higher the total score, the greater the severity of dry mouth [29].

\section{Statistical analysis}

The data are expressed in frequencies and percentages for qualitative variables and as mean \pm standard error for quantitative ones, unless otherwise indicated. Significance was expressed at the $\mathrm{P}<0.05$ level. When appropriate, a $\chi^{2}$ test for categorical data and analysis of variance for continuous data were used. Differences in score values at baseline, and after 1, 2,3 and 6 months were analyzed using the Student's $t$-test. The SPSS for Windows version 15.0 statistical package (SPSS Inc, Chicago, IL, USA) was used for the statistical analysis.

\section{Results}

In the first phase of the study, 198 convicts, 22 female, underwent screening for HCV. Table 1 reports the characteristics of the screened patients. There were no differences between the 2 sexes. Fifty patients (25.25\%) had a positive HCV-RNA test. Table 2 reports the clinical data of the $50 \mathrm{HCV}$ positive patients. The percentage of genotype 1a was higher in male convicts $(41.9 \%$ vs. $0 \%, \mathrm{P}=0.02)$, whereas the percentage of genotype $3 \mathrm{a}$ was not significantly higher in females $(71.4 \%$ vs. $39.5 \%, \mathrm{P}=0.092$. $\mathrm{HCV}$ viral load was significantly higher in male compared to female convicts $(\mathrm{P}=0.01)$. In addition, the Fibroscan score was different between males and females; in female patients there was a higher percentage of F3 score (57.2\% vs. $20.9 \%, \mathrm{P}=0.04)$. Regarding the risk factors, males included a significantly higher percentage of PWID (76.7\% vs. 28.65 , $\mathrm{P}<0.001$ ), while sexual promiscuity was mainly recognized in the female population ( $28.6 \%$ vs. $4.7 \%, \mathrm{P}=0.03$ ). All 50 patients underwent therapy with DAAs for HCV infection. There were no side-effects and none stopped the therapy. In 2 patients, F4 on transient elastography, the therapy lasted 16 weeks, while for the remaining patients, who were F0, F1, F2 or F3, the therapy lasted 8 weeks. The treatment was successful in all patients and resulted in negative HCV-RNA even after 1 month from the start of treatment. Laboratory monitoring at 5 months, in the patients who underwent the 8 -week therapy, and 7 months, in the patients who underwent the 16-week therapy, revealed negative HCV-RNA in all patients, achieving an SVR12 of $100 \%$. None of the screened patients were under treatment that could influence the course of OLP (e.g., immunosuppressive therapy and/or steroids) or predispose to hyposalivation (e.g., anticholinergics).

Table 1 Demographic and clinical data of screened population

\begin{tabular}{|c|c|c|c|c|}
\hline Characteristics & Total N (\%) & Males & Females & P-value \\
\hline Sex & $198(100 \%)$ & $176(88.9 \%)$ & $22(11.1 \%)$ & \\
\hline Age (years) & $41.25 \pm 9.7$ & $41.24 \pm 9.77$ & $41.36 \pm 9.31$ & 0.95 \\
\hline Anti-HIV Ab+ & $1(0.5 \%)$ & $1(0.6 \%)$ & $0(0 \%)$ & 0.47 \\
\hline Anti-HCV Ab+ & $50(25.3 \%)$ & $43(24.4 \%)$ & $7(31.8 \%)$ & 0.18 \\
\hline $\begin{array}{l}\text { Risk factor } \\
\text { - None } \\
\text { - PWID } \\
\text { - Sex promiscuity } \\
\text { - MSM }\end{array}$ & $\begin{array}{c}104(52.5 \%) \\
76(38.4 \%) \\
13(6.6 \%) \\
5(2.5 \%)\end{array}$ & $\begin{array}{c}89(50.6 \%) \\
71(40.3 \%) \\
11(6.3 \%) \\
5(2.8 \%)\end{array}$ & $\begin{array}{c}15(68.2 \%) \\
5(22.7 \%) \\
2(9.1 \%) \\
\text { N/A }\end{array}$ & $\begin{array}{c}0.125 \\
0.11 \\
0.61 \\
\text { N/A }\end{array}$ \\
\hline AST baseline & $35.02 \pm 17.53$ & $35.49 \pm 17.79$ & $31.23 \pm 15.19$ & 0.72 \\
\hline ALT baseline & $36.84 \pm 17.82$ & $36.91 \pm 18.17$ & $36.27 \pm 15.02$ & 0.65 \\
\hline Platelets & $254.95 \pm 71.83$ & $255.68 \pm 72.94$ & $249.14 \pm 63.52$ & 0.25 \\
\hline HBsAg + & $(1 \%)$ & $2(1.1 \%)$ & $0(0 \%)$ & 0.3 \\
\hline $\begin{array}{l}\text { Comorbidities } \\
\text {-None } \\
\text {-Hypertension } \\
\text {-Diabetes } \\
\text {-Cardiovascular } \\
\text {-COPD } \\
\text {-Dyslipidemia } \\
\text {-NAFLD } \\
\text {-IBD } \\
\text {-Neuro/Psyc } \\
\text {-Prostatic hypertrophy }\end{array}$ & $\begin{array}{c}119(60.1 \%) \\
17(8.6 \%) \\
20(10.1 \%) \\
6(3 \%) \\
17(8.6 \%) \\
18(9.1 \%) \\
2(1.1 \%) \\
4(2 \%) \\
9(8.5 \%) \\
2(1.1 \%)\end{array}$ & $\begin{array}{c}106(60.2 \%) \\
19(10.8 \%) \\
18(10.2 \%) \\
5(2.9 \%) \\
16(9 \%) \\
16(9 \%) \\
2(1.1 \%) \\
3(1.7 \%) \\
8(4.5 \%) \\
2(1.1 \%)\end{array}$ & $\begin{array}{c}13(59.1 \%) \\
2(9.1 \%) \\
2(9 \%) \\
1(4.5 \%) \\
1(4.5 \%) \\
1(4.5 \%) \\
0(0 \%) \\
1(4.5 \%) \\
1(4.5 \%) \\
\text { N/A }\end{array}$ & $\begin{array}{c}0.86 \\
1 \\
0.28 \\
0.90 \\
0.90 \\
0.61 \\
0.37 \\
1 \\
\text { N/A }\end{array}$ \\
\hline
\end{tabular}

HIV, human immunodeficiency virus; $H C V$, hepatitis $C$ virus; $P$ WID, patients who inject drugs intravenously; $M S M$, men who have sex with men; AST, aspartate aminotransferase; ALT, alanine aminotransferase; COPD, chronic obstructive pulmonary disease; NAFLD, nonalcoholic fatty liver disease; IBD, inflammatory bowel disease; Neuro/Psyc, neuropsychiatric disease 
Table 2 Demographic and clinical data of the HCV population

\begin{tabular}{|c|c|c|c|c|}
\hline Characteristics & Total N (\%) & Males & Females & P-value \\
\hline Sex & $50(100 \%)$ & $43(86 \%)$ & $7(14 \%)$ & \\
\hline Age (years) & $41.48 \pm 11.68$ & $42.05 \pm 11.75$ & $38 \pm 11.48$ & 0.59 \\
\hline Anti-HIV Ab+ & $1(2 \%)$ & $1(2.3 \%)$ & $0(0 \%)$ & 0.69 \\
\hline $\begin{array}{l}\text { Genotype } \\
-1 \mathrm{a} \\
-1 \mathrm{~b} \\
-2-3 \mathrm{a} \\
-4 \mathrm{~b}\end{array}$ & $\begin{array}{c}18(36 \%) \\
5(10 \%) \\
2(4 \%) \\
22(44 \%) \\
3(6 \%)\end{array}$ & $\begin{array}{c}18(41.9 \%) \\
3(7 \%) \\
2(4.7 \%) \\
17(39.5 \%) \\
3(7 \%)\end{array}$ & $\begin{array}{c}0(0 \%) \\
2(28.6 \%) \\
0(0 \%) \\
5(71.4 \%) \\
0(0 \%)\end{array}$ & $\begin{array}{c}0.02 \\
0.8 \\
0.57 \\
0.092 \\
0.48\end{array}$ \\
\hline HCV-RNA load & $3338586 \pm 4448741.78$ & $3777148.84 \pm 4650977.93$ & $644557.14 \pm 601636.96$ & 0.01 \\
\hline $\begin{array}{l}\text { Fibroscan } \\
\text {-F1 } \\
\text {-F2 } \\
\text {-F3 } \\
\text {-F4 }\end{array}$ & $\begin{array}{c}0(0 \%) \\
35(70 \%) \\
13(26 \%) \\
2(4 \%)\end{array}$ & $\begin{array}{c}0(0 \%) \\
32(74.4 \%) \\
9(20.9 \%) \\
2(4.7 \%)\end{array}$ & $\begin{array}{c}0(0 \%) \\
3(42.9 \%) \\
4(57.1 \%) \\
0(0 \%)\end{array}$ & $\begin{array}{l}\text { N/A } \\
0.09 \\
0.04 \\
0.57\end{array}$ \\
\hline $\begin{array}{l}\text { Risk Factor } \\
\text { - None } \\
\text { - PWID } \\
\text { - Sex promiscuity } \\
\text { - MSM }\end{array}$ & $\begin{array}{c}8(16 \%) \\
35(70 \%) \\
4(8 \%) \\
3(6 \%)\end{array}$ & $\begin{array}{c}5(11.6 \%) \\
33(76.7 \%) \\
2(4.7) \\
3(7 \%)\end{array}$ & $\begin{array}{c}3(42.9 \%) \\
2(28.65 \%) \\
2(28.6 \%) \\
\text { N/A }\end{array}$ & $\begin{array}{c}0.2 \\
0.009 \\
0.03 \\
\text { N/A }\end{array}$ \\
\hline AST baseline & $33.36 \pm 15.38$ & $32.47 \pm 14.51$ & $38.86 \pm 20.42$ & 0.57 \\
\hline ALT baseline & $37.58 \pm 24.58$ & $37.21 \pm 25.56$ & $39.86 \pm 18.78$ & 0.66 \\
\hline Platelets & $215.20 \pm 53.35$ & $214.98 \pm 54.37$ & $216.57 \pm 50.5$ & 0.65 \\
\hline HBsAg + & $0(0 \%)$ & - & - & \\
\hline $\begin{array}{l}\text { Comorbidities } \\
\text {-None } \\
\text {-Hypertension } \\
\text {-Diabetes } \\
\text {-Cardiovascular } \\
\text {-COPD } \\
\text {-Dyslipidemia } \\
\text {-IBD }\end{array}$ & $\begin{array}{c}34(68 \%) \\
5(10 \%) \\
5(10 \%) \\
1(2 \%) \\
4(8 \%) \\
3(6 \%) \\
1(2 \%)\end{array}$ & $\begin{array}{c}29(67,4 \%) \\
4(9.3 \%) \\
5(11.7 \%) \\
1(2.3 \%) \\
3(7 \%) \\
4(9.3 \%) \\
1(2.3 \%)\end{array}$ & $\begin{array}{c}5(71.4 \%) \\
1(14.3 \%) \\
0(0 \%) \\
0(0 \%) \\
1(14.3 \%) \\
0(0 \%) \\
0(0 \%)\end{array}$ & $\begin{array}{l}0.69 \\
0.57 \\
0.69 \\
0.51 \\
0.48 \\
0.69\end{array}$ \\
\hline
\end{tabular}

HIV, human immunodeficiency virus; HCV, hepatitis C virus; PWID, patients who inject drugs intravenously; MSM, men who have sex with men; AST, aspartate aminotransferase; ALT, alanine aminotransferase; COPD, chronic obstructive pulmonary disease; IBD, inflammatory bowel disease

OLP lesions were recognized in 4 (8\%) patients and hyposalivation was recognized in 17 patients (34\%). No worsening of OLP lesions occurred during DAA therapy. On clinical examination at 1,2 and 3 months we found improvement in the lesions in all patients. At 6 months the OLP disappeared in 3 patients, while there was an improvement without disappearance in the other one (mean REU score $10.13 \pm 4.76$ vs. $2 \pm 4, \mathrm{P}=0.009$ ). At 6 months there was disappearance of hyposalivation in 5 patients (29.4\%), improvement in 10 patients $(58.8 \%)$ and no change in 2 patients (mean CODS $4.71 \pm 1.72$ vs. $0.06 \pm 0.24, \mathrm{P}<0.001$ ).

\section{Discussion}

HCV infection affects about $26 \%$ of the imprisoned people worldwide, while within Italian prisons its prevalence varies from $22-38 \%$ [6]. In our study, we enrolled 198 patients and
50 of these tested positive for $\mathrm{HCV}$ infection. We found a prevalence of $25.25 \%$, which reflects the conditions in Italian prisons and the presence of people of high risk, such as PWID and those living with HIV. Our study group presented a different prevalence of PWID and sexual promiscuity across gender. In particular, we recognized a higher prevalence of PWID in the male population and greater sexual promiscuity in female inmates, which is consistent with several studies [30,31]. Similarly, our data confirmed the higher prevalence of $\mathrm{HCV}$ genotype 1a in the male population, as previously reported [32,33]. All $50 \mathrm{HCV}$ positive inmates underwent antiviral treatment with glecaprevir/pibrentasvir (Maviret), achieving SVR 12 weeks after the end of treatment. These results support the data of some previous studies that reported high efficacy of new DAAs, as well as lower toxicity and with rapid action [21,22]. Furthermore, none of the patients interrupted the treatment nor did any have adverse events typical of IFN, demonstrating the reliability and safety of DAA therapy [23]. 
From the assessments carried out during the oral screening of HCV-positive inmates, we found 4 cases of OLP, so the percentage of OLP in our study group was $8 \%$. This prevalence differs from the values found in the general population, which range from $0.5-2 \%$ [10]. This could be explained by the presence of HCV-positive patients in the sample examined. Indeed, our data are consistent with various studies that have reported a higher risk of OLP in HCV-infected patients than in the noninfected [11]. In the literature it is reported that the eradication of the HCV virus with DAAs results in improvement in extrahepatic conditions, such as cardiovascular, metabolic, renal, hematologic complications [34,35], and lichen planus [26]. Effectively, at the end of DAA treatment we recognized a significant improvement in OLP lesions, with disappearance in 3 cases (75\%) and clinical improvement in the remaining one. Our results are consistent with the study by Nagao et al [25] which, evaluating 7 patients with HCVrelated OLP, demonstrated the disappearance of the lesions in 4 patients and improvement in 3 patients after DAA therapy. Indeed, since we observed improvements in OLP lesions in all DAAs treated patients, we could assume that in these patients the OLP was related to HCV. Furthermore, our findings seem to be consistent with the results of previous studies [36,37] that hypothesized a correlation between HCV and OLP. Conversely, a recent case series and literature review showed persistent or worsened lichen planus in almost $18 \%$ of HCV patients under treatment with DAAs, with a better prognosis in patients with only oral manifestations [38]. Further studies are needed to better characterize the effect of DAAs on lichen planus.

The correlation between HCV and hyposalivation is still poorly investigated. We found hyposalivation in 34\% of $\mathrm{HCV}$ inmates, that is almost 2-fold higher than previously reported [18]; moreover, we described for the first time a significant improvement in hyposalivation in patients treated with DAA. Indeed, there is no evidence regarding changes in hyposalivation in response to DAA therapy in $\mathrm{HCV}$ patients. Although the correlation between hyposalivation and HCV has not yet been demonstrated, our clinical experience tends to suggest an improvement in hyposalivation, even if it was not possible to substantiate the diagnosis of hyposalivation with salivary gland biopsy and related blood chemistry tests. Another strength of the present study is that our findings offer a screenshot of the Italian convicted population.

There are some limitations in this study. One is the relatively small sample size and the heterogeneity of patients, which might have limited the generalizability of the findings, especially regarding gender differences. Another limitation is that the design of the study weakens our findings in comparison to results from a prospective longitudinal study, which would be necessary to establish a causal relationship between the improvement in oral lesions and the DAA therapy. Moreover, there were no data about the evolution of oral lesions in non$\mathrm{HCV}$ inmates.

The results of the current study suggest that more regular screening of oral lesions when evaluating $\mathrm{HCV}$-positive inmates might help disclose the presence of OLP and hyposalivation. Furthermore, the study showed an improvement in OLP and hyposalivation in imprisoned patients with $\mathrm{HCV}$ infection after therapy with DAAs. Studies conducted on larger samples of patients are needed to confirm that DAA therapy in HCVinfected patients leads to an improvement in HCV-related oral lesions.

\section{Summary Box}

\section{What is already known:}

- Prison represents a confined environment characterized by great exposure to and risk of hepatitis $\mathrm{C}$ virus (HCV) infection

- Oral lichen planus and hyposalivation are extrahepatic manifestation of $\mathrm{HCV}$ infection

- The efficacy of HCV direct antiviral agents (DAAs) on oral manifestations of $\mathrm{HCV}$ is still under debate

\section{What the new finding is:}

- Oral lichen planus and hyposalivation is more common in HCV inmates than in the general population with $\mathrm{HCV}$ infection

- DAAs could improve HCV-related oral lichen planus and hyposalivation

- An individual assessment of the oral cavity should be incorporated into regular screening in convicts, especially in those with risk factors

\section{References}

1. Crowley D, Van Hout MC, Lambert JS, Kelly E, Murphy C, Cullen W. Barriers and facilitators to hepatitis C (HCV) screening and treatment-a description of prisoners' perspective. Harm Reduct J 2018;15:62.

2. Westbrook RH, Dusheiko G. Natural history of hepatitis C. J Hepatol 2014;61(1 Suppl):S58-S68.

3. Voller F, Silvestri C, Martino G, et al. Health conditions of inmates in Italy. BMC Public Health 2016;16:1162.

4. Mason LM, Duffell E, Veldhuijzen IK, Petriti U, Bunge EM, Tavoschi L. Hepatitis B and C prevalence and incidence in key population groups with multiple risk factors in the EU/EEA: a systematic review. Euro Surveill 2019;24:1800614.

5. Chen CP, Cheng CY, Zou H, et al. Evaluation of cost-effectiveness of peginterferon plus ribavirin for chronic hepatitis $\mathrm{C}$ treatment and direct-acting antiviral agents among HIV-infected patients in the prison and community settings. J Microbiol Immunol Infect 2019;52:556-562.

6. Masarone M, Caruso R, Aglitti A, et al. Hepatitis C virus infection in jail: difficult-to-reach, not to-treat. Results of a point-of-care screening and treatment program. Dig Liver Dis 2020;52:541-546.

7. Carrozzo M, Scally K. Oral manifestations of hepatitis C virus infection. World J Gastroenterol 2014;20:7534-7543.

8. Cruz-Pamplona M, Margaix-Muñoz M, Sarrión-Pérez MG. Dental considerations in patients with liver disease. J Clin Exp Dent 2011;3:e127-e134. 
9. Chiang CP, Yu-Fong Chang J, Wang YP, Wu YH, Lu SY, Sun A. Oral lichen planus - Differential diagnoses, serum autoantibodies, hematinic deficiencies, and management. J Formos Med Assoc 2018;117:756-765.

10. Al-Hashimi I, Schifter M, Lockhart PB, et al. Oral lichen planus and oral lichenoid lesions: diagnostic and therapeutic considerations. Oral Surg Oral Med Oral Pathol Oral Radiol Endod 2007;103 Suppl S25:e1-e12.

11. Mester A, Lucaciu O, Ciobanu L, Apostu D, Ilea A, Campian RS. Clinical features and management of oral lichen planus (OLP) with emphasis on the management of hepatitis $\mathrm{C}$ virus (HCV)-related OLP. Bosn J Basic Med Sci 2018;18:217-223.

12. Lavanya N, Jayanthi P, Rao UK, Ranganathan K. Oral lichen planus: an update on pathogenesis and treatment. J Oral Maxillofac Pathol 2011;15:127-132.

13. Zhao ZZ, Sugerman PB, Zhou XJ, Walsh LJ, Savage NW. Mast cell degranulation and the role of T cell RANTES in oral lichen planus. Oral Dis 2001;7:246-251.

14. Khan A, Shirlaw PJ. Dry mouth and Sjögren's syndrome: an overview. Prim Dent J 2016;5:70-74.

15. Tanasiewicz M, Hildebrandt T, Obersztyn I. Xerostomia of various etiologies: a review of the literature. Adv Clin Exp Med 2016;25:199-206.

16. Millsop JW, Wang EA, Fazel N. Etiology, evaluation, and management of xerostomia. Clin Dermatol 2017;35:468-476.

17. Osailan SM, Pramanik R, Shirlaw P, Proctor GB, Challacombe SJ. Clinical assessment of oral dryness: development of a scoring system related to salivary flow and mucosal wetness. Oral Surg Oral Med Oral Pathol Oral Radiol 2012;114:597-603.

18. Ferreiro MC, Prieto MH, Rodríguez SB, Vázquez RL, Iglesias AC, Dios PD. Whole stimulated salivary flow in patients with chronic hepatitis C virus infection. J Oral Pathol Med 2002;31:117-120.

19. Grossmann SM, Teixeira R, Oliveira GC, et al. Xerostomia, hyposalivation and sialadenitis in patients with chronic hepatitis $\mathrm{C}$ are not associated with the detection of HCV RNA in saliva or salivary glands. J Clin Pathol 2010;63:1002-1007.

20. de Mattos Camargo Grossmann S, Teixeira R, de Oliveira GC, do Carmo MA. Detection of HCV RNA in saliva does not correlate with salivary flow or xerostomia in patients with chronic hepatitis C. Oral Surg Oral Med Oral Pathol Oral Radiol Endod 2010;109:851-856.

21. González-Grande R, Jiménez-Pérez M, González Arjona C, Mostazo Torres J. New approaches in the treatment of hepatitis C. World J Gastroenterol 2016;22:1421-1432.

22. De Pace V, Morelli MC, Ravaioli M, et al. Efficacy, safety, and predictors of direct-acting antivirals in hepatitis $\mathrm{C}$ virus patients with heterogeneous liver diseases. New Microbiol 2019;42:189-196.

23. Vespasiani-Gentilucci U, Galati G, Gallo P, De Vincentis A, Riva E, Picardi A. Hepatitis C treatment in the elderly: New possibilities and controversies towards interferon-free regimens. World $J$ Gastroenterol 2015;21:7412-7426.

24. Khaliq S, Raza SM. Current status of direct acting antiviral agents against hepatitis $\mathrm{C}$ virus infection in Pakistan. Medicina (Kaunas)
2018;54:80.

25. Nagao Y, Kimura K, Kawahigashi Y, Sata M. Successful treatment of hepatitis c virus-associated oral lichen planus by interferon-free therapy with direct-acting antivirals. Clin Transl Gastroenterol 2016;7:e179.

26. El-Serag HB, Christie IC, Puenpatom A, Castillo D, Kanwal F, Kramer JR. The effects of sustained virological response to direct-acting anti-viral therapy on the risk of extrahepatic manifestations of hepatitis C infection. Aliment Pharmacol Ther 2019;49:1442-1447.

27. Amato A, Caggiano M, Amato M, Moccia G, Capunzo M, De Caro F. Infection control in dental practice during the COVID-19 pandemic. Int J Environ Res Public Health 2020;17:4769.

28. Piboonniyom SO, Treister N, Pitiphat W, Woo SB. Scoring system for monitoring oral lichenoid lesions: a preliminary study. Oral Surg Oral Med Oral Pathol Oral Radiol Endod 2005;99:696-703.

29. Jager DHJ, Bots CP, Forouzanfar T, Brand HS. Clinical oral dryness score: evaluation of a new screening method for oral dryness. Odontology 2018;106:439-444.

30. Wenger PJ, Rottnek F, Parker T, Crippin JS. Assessment of hepatitis $\mathrm{C}$ risk factors and infection prevalence in a jail population. Am J Public Health 2014;104:1722-1727.

31. Degenhardt L, Peacock A, Colledge S, et al. Global prevalence of injecting drug use and sociodemographic characteristics and prevalence of HIV, HBV, and HCV in people who inject drugs: a multistage systematic review. Lancet Glob Health 2017;5:e1192-e1207.

32. Elasifer HA, Agnnyia YM, Al-Alagi BA, Daw MA. Epidemiological manifestations of hepatitis $C$ virus genotypes and its association with potential risk factors among Libyan patients. Virol $J$ 2010;7:317.

33. Andriulli A, Morisco F, Ippolito AM, et al. HCV genotype 1 subtypes (1a and $1 \mathrm{~b}$ ): similarities and differences in clinical features and therapeutic outcome. Hepatol Int 2015;9:52-57.

34. Mohanty A, Salameh S, Butt AA. Impact of direct acting antiviral agent therapy upon extrahepatic manifestations of hepatitis $C$ virus infection. Curr HIV/AIDS Rep 2019;16:389-394.

35. Adinolfi LE, Petta S, Fracanzani AL, et al. Impact of hepatitis C virus clearance by direct-acting antiviral treatment on the incidence of major cardiovascular events: a prospective multicentre study. Atherosclerosis 2020;296:40-47.

36. Alaizari NA, Al-Maweri SA, Al-Shamiri HM, Tarakji B, Shugaa-Addin B. Hepatitis C virus infections in oral lichen planus: a systematic review and meta-analysis. Aust Dent $J$ 2016;61:282-287.

37. Nosratzehi T. Oral lichen planus: an overview of potential risk factors, biomarkers and treatments. Asian Pac J Cancer Prev 2018;19:1161-1167.

38. Barajas L, Steuer M, Amerson E. Variable clinical course of lichen planus following hepatitis C cure with direct-acting antivirals: A case series and literature review. J Am Acad Dermatol 2021;84:1142-1146. 